\title{
AGRARIAN- Automatic Plant Irrigation System
}

\author{
Tanveer Anand \\ BE, Information Technology, \\ Thadomal Shahani Engineering College. \\ Diploma, Computer Engineering, \\ Shri Bhaugubhai Mafatlal Polytechnic. \\ 401/B Dheeraj Heritage Residency 1, \\ off link rd extention, \\ opp Shastrinagar, Santacruz(W), \\ Mumbai-40005
}

\begin{abstract}
Agriculture has always been a labor-intensive work and most of the information that has been collected is manual. Hence it becomes really difficult to maintain records of the conditions of the soil and whether it will be able to sustain agricultural activities. This paper discuses 'AGRARIAN' a project with a purpose to maintain a highly computed system that helps in the irrigation of an agricultural field by taking into consideration the parameters like temperature, moisture and humidity of the soil in which the crops have been planted. The system is used for comparing the values recorded against a minimum threshold set which may cause the valve to open causing the water to flow into the soil.
\end{abstract}

\section{General Terms}

Plant, Automatic Irrigation, Microcontroller-8085, interfacing with ADC 0808

\section{Keywords}

Agrarian, Microcontroller, Sensors, Soil, Solenoid Valve.

\section{INTRODUCTION}

Agriculture has always played an important role in the economic development of a nation as well as the growth of crops and land cultivation. In order to maintain a steady growth of crops the resources should always be in abundant supply and within an appropriate amount without deteriorating the soil condition.

Manual labor has always been the focal of the agricultural industry without taking into consideration the conditions of the soil. Automated systems present today have a design that includes a micro-controller system for processing the soil conditions and follows the principle of continuous water logging by using various sensors, thus checking only the soil conditions but not maintaining any records of the soil behavior over time.

\section{PROBLEM DEFINITON WITH SCOPE}

In this project multiple sensors are used, such as temperature, humidity and moisture for the better growth of the plant. These components are interfaced with the Microcontroller which is used to forward the values from these sensors to the $\mathrm{PC}$

The PC runs a software which reads the data sent by the Microcontroller from the port through which the two are connected. The values are stored by the software in the respective fields of temperature, moisture and humidity.
Now a comparison is made by the system to the values read and processes a command to the Micro controller whether or not to supply the required amount of water to the plant.

This project however depicts a communication mechanism that has been developed between a Micro-Controller and PC and amongst various sensors in order to maintain the resources required for the growth of the plant in appropriate amount

\section{PROPOSED SYSTEM}

The project discussed here, makes use of a very popular P89V51RD2 micro controller, ADC 0808, MAX 232, Visual Basic 6.0 for interfacing with the computer. The important components we are using here are ADC0808 and our Microcontroller.

The ADC0808 will fetch the inputs from the various sensors and forward it to the Micro controller. The micro controller in turn communicates with the PC for decision-making and appropriate signal is issued again to the micro controller, which decides whether to turn on or off the water supply.

It basically follows the principle of continuous data logging from the soil contents by using various sensors and feeding the output of the sensors to the PC

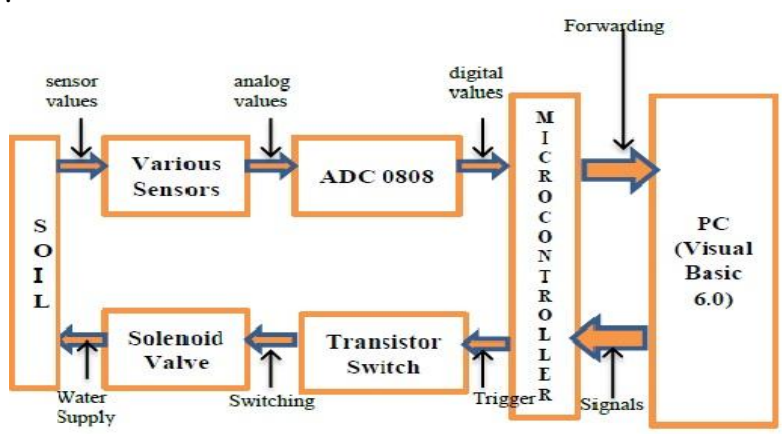

Figure 1: Proposed System

\subsection{Sensors}

The sensors used in the above system are moisture that makes use of aluminum plates, temperature which uses a LM35 chip and SY-HS 220 as a humidity sensor.

\subsubsection{Moisture Sensors}

Aluminum plates are conductive materials which are used to sense the moisture in the soil. We apply crocodile clips to each aluminum plate and let it rest in the soil to measure the moisture levels. Plates conduct only when there is excessive moisture in the soil and hence the output voltage given to the 
ADC will be more. One terminal is connected to the ground and the other is connected the input pin of the ADC ie the variable out of the aluminum plate.

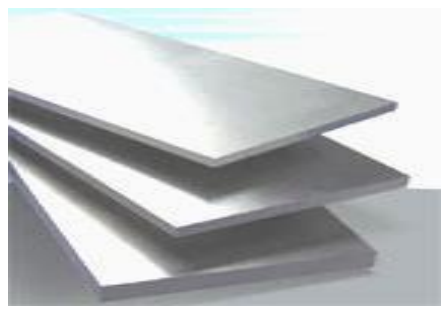

Fig 1.1: Aluminum Plates

\subsubsection{Temperature Sensors}

LM35 chip (temperature sensor) is a highly integrated circuit that produces an output voltage that is linearly proportional to a value in Centigrade $\left({ }^{\circ} \mathrm{C}\right)$. The LM35 chip can operate between $-55{ }^{\circ} \mathrm{C}$ and $+150{ }^{\circ} \mathrm{C}$ and has the basic advantage that it doesn't require any prior calibration from the user.
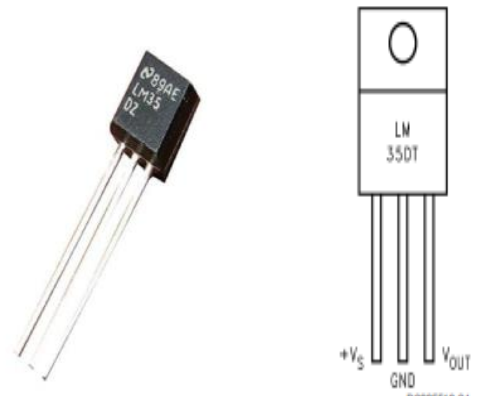

Fig 1. 2: LM35 chip and pin diagram

\subsubsection{Humidity Sensors}

SY-HS 220 (Humidity Sensor) is a very reliable humidity sensor that convert the surrounding RH\% into its equivalent D.C. output voltage.

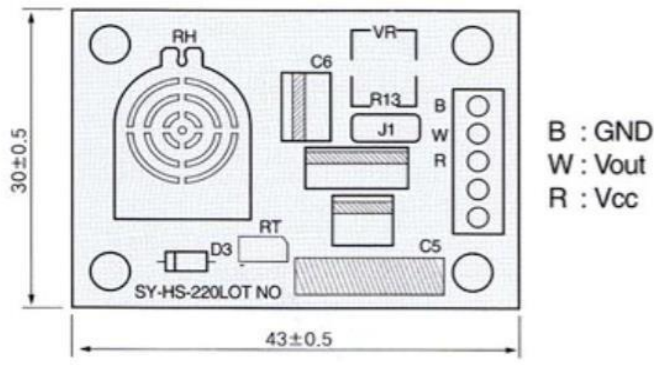

Fig 1. 3: Layout diagram of SY-HS-220

\subsection{ADC (0808)}

ADC stands for analog to digital converter a data acquisition component which is a monolithic CMOS device with an 8 bit analog to digital converter ,8 channel multiplexer and microprocessor compatible control logic.

The converter features a high impedance chopper stabilized comparator, a 256R voltage divider with analog switch tree and a successive approximation register..

Hence, the function of the ADC here is to take the analog signal from the sensors and pass the digital signal to the microcontroller

\subsection{Micro Controller (P89V51RD2)}

P89V51RD2 is an 80C51 microcontroller with 16/32/64 kB flash and $1024 \mathrm{~B}$ of data RAM. We choose to run the application with the conventional 80C51 clock rate (12 clocks per machine cycle).

The flash program memory supports both parallel programming and in serial ISP. Parallel programming mode offers gang programming at high speed. ISP allows a device to be reprogrammed in the end product under software control.

The Micro Controller reads the input digital signal from the ADC and puts these values on its output pins so that it can be forwarded to the computer software.

The ADC is interfaced at pins from AD0 to AD7 where the signals are sent and these signals are forwarded on the port 3 pins.

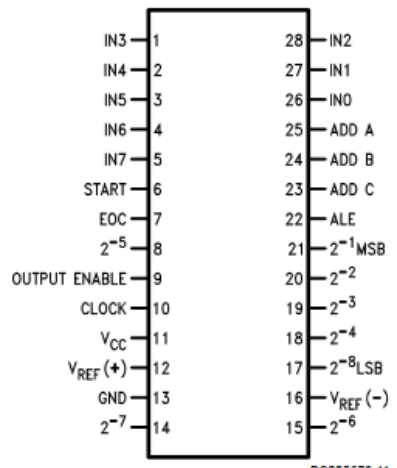

Fig 1. 4: Pin diagram of ADC 0808

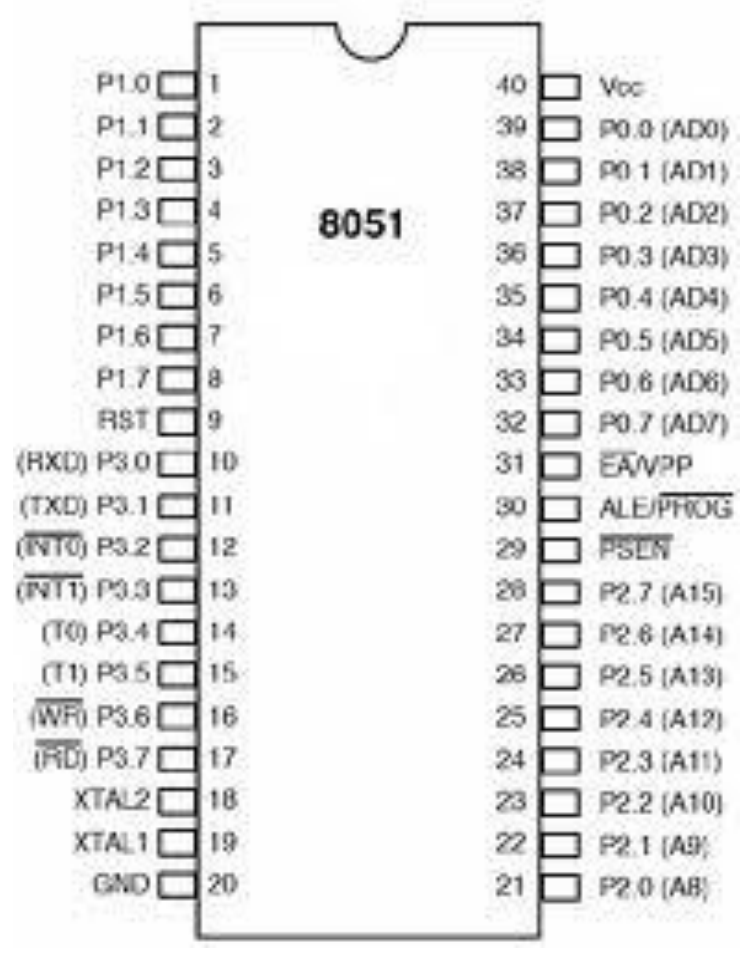

Fig 1. 5: 8051 pin diagram 


\subsection{Forwarding System}

This system includes a MAX 232 chip, which is used for serial transmission of digital signals. This chip is interfaced onto the Port 3 pins of the Micro Controller where the digital signals are put for the chip to read them.

The Max 232 interfaces with a DB 9 serial connector where the signals to be transmitted and received are present on the Rxd and Txd pins.

The data is transmitted only when the signals RTS (Request To Send) and CTS(Clear To Send) are active that is if a high impedence state is encountered.

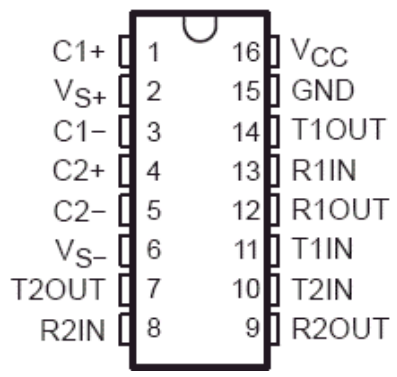

Fig 1. 6: MAX 232 Pin diagram

\subsection{Graphical User Interface}

The GUI of the system is built on the Visual Basic Software (Version 6.0) that runs in the background. The software is created in such a way that the values read from the serial port are bifurcated into their respective fields created (temperature, moisture and humidity).

The software has been initialized with a threshold value set based in accordance to the soil quality. Comparisons are made within the system that runs an algorithm and makes a decision whether or not to supply water.

The decision made causes the system to send a digital high logic (' 1 ') or a digital low logic (' 0 ') back to the Micro Controller.

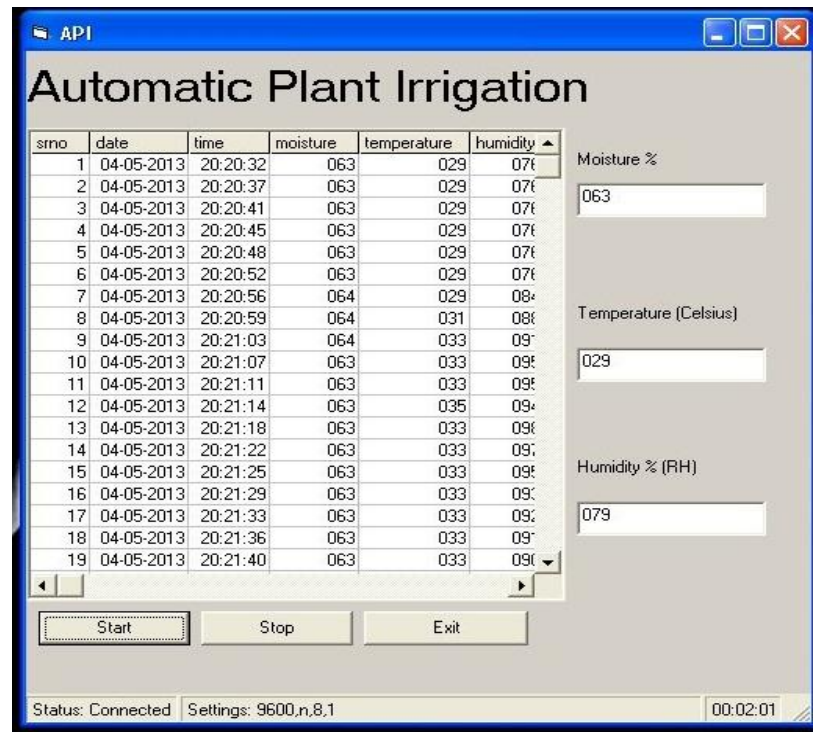

Fig 1. 7: GUI of Software System

\subsection{Transistor Switching}

Transistors are commonly used electronic switches, for highpower applications as well as for low-power applications such as logic gates.
In this Project the transistor acts as a make and break circuit hence, takes the signals received from the microcontroller and depending on the logic the switch is connected to the system or disconnected.

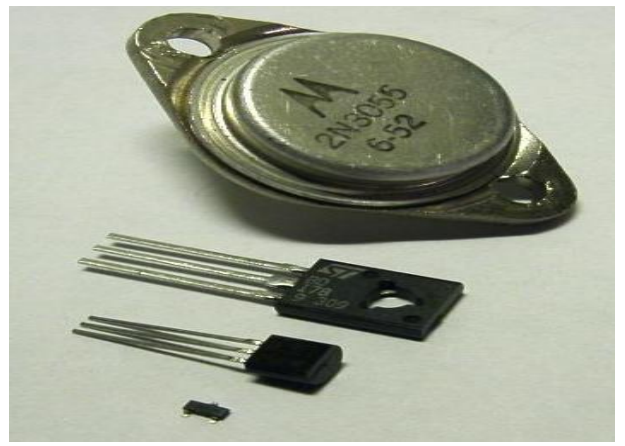

Fig 1. 8: Transistor Switch

\subsection{Relay Switches}

A relay is an electrically operated switch and uses an electromagnet to operate a switching mechanism mechanically. It is used whereever necessary to control a circuit by a low-power signal (with complete electrical isolation between control and controlled circuits), or where several circuits must be controlled by one signal.

A type of relay used here is a high power, required to directly control an solenoid valve. It is used as a means of providing a signal to open the valve for supplying water.

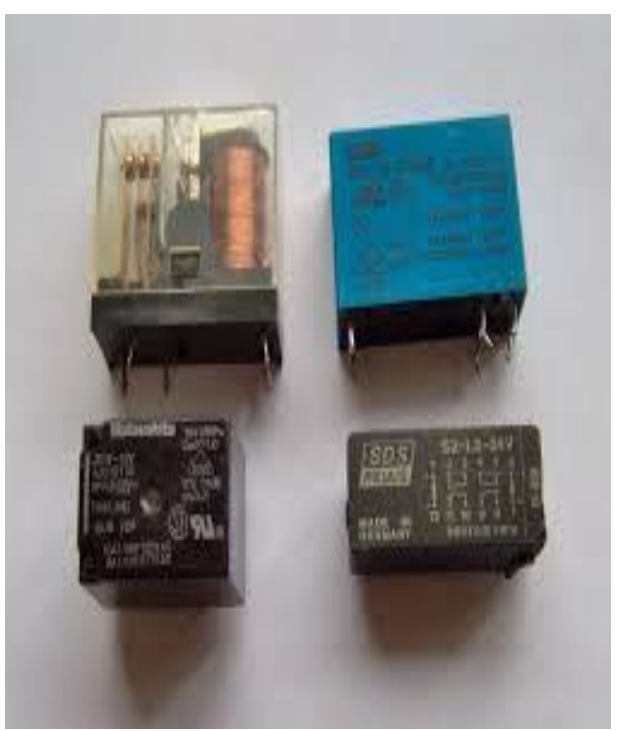

Fig 1.9: Relay as a Switch

\subsection{Solenoid Valve}

A solenoid valve is an electromechanically operated valve. The valve is controlled by an electric current through a solenoid: in the case of a two-port valve the flow is switched on or off; in the case of a three-port valve, the outflow is switched between the two outlet ports. Multiple solenoid valves can be placed together on a manifold.

Solenoid valves are the most frequently used control elements in fluidics. Their tasks are to shut off, release, dose, distribute or mix fluids. Solenoids offer fast and safe switching, high reliability, long service life, good medium compatibility of the materials used, low control power and compact design. 

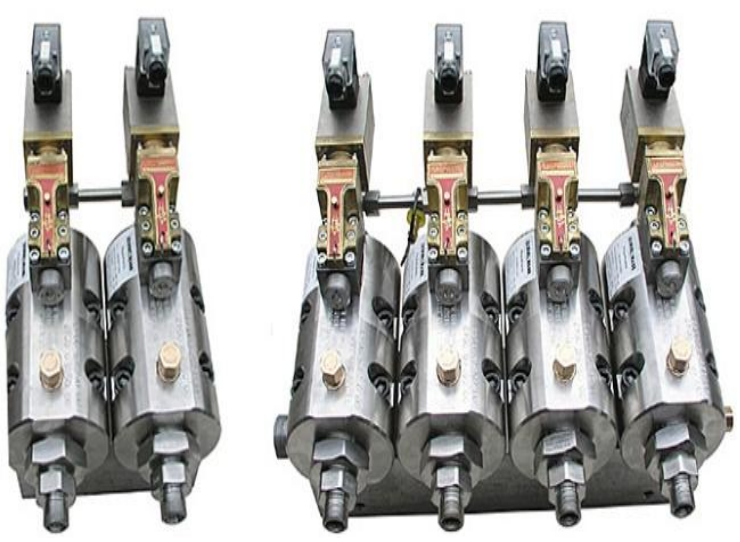

Fig 1. 1: Solenoid Valve

\section{SYSTEM ARCHITECTURE}

The circuit diagram shows how the entire system is assembled on a PCB (Printed Circuit Board). It clearly depicts how each instrument is interfaced with each other so that the signals can be easily transmitted and processed from one region to another.

On the PCB the track layout is made and care should be taken that the tracks do not collide with each other else it may lead to shorting the circuit.

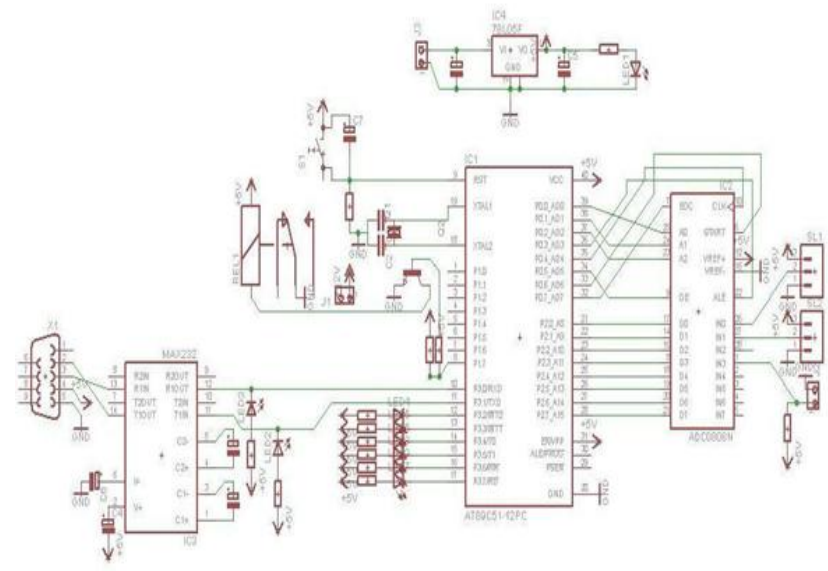

Fig 2. Circuit Diagram of the proposed system

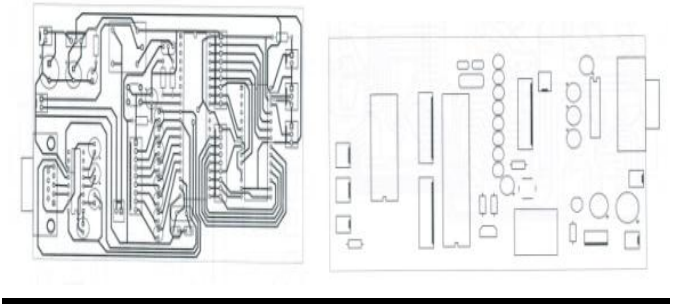

Fig 2. 1 Track and Component Layout on PCB

\section{CONTROL FLOW}

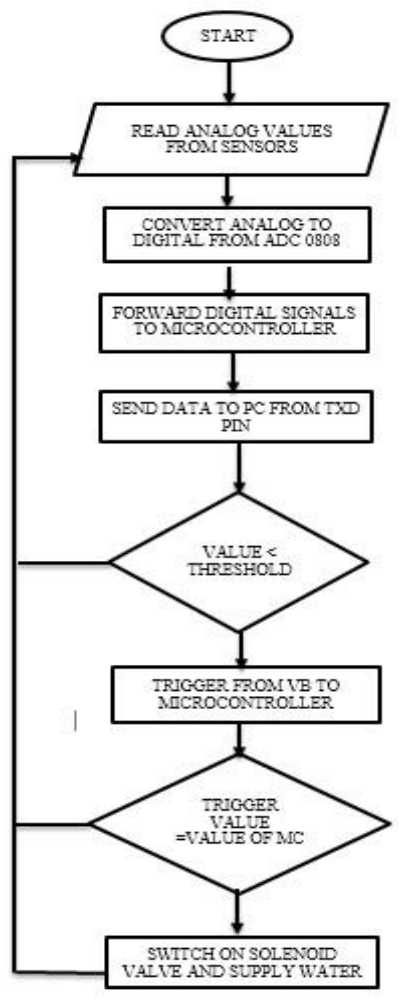

Fig 2. 2 Flow chart

The system starts working when the user presses start on the VB GUI provided.As the sensors are continously sensning values the digital signals are recoredd in the database at the software system.

The decision control logic is mainatined by the softawre and depending upon the comparisons made from the threshold values the water supply system is switched on or off.

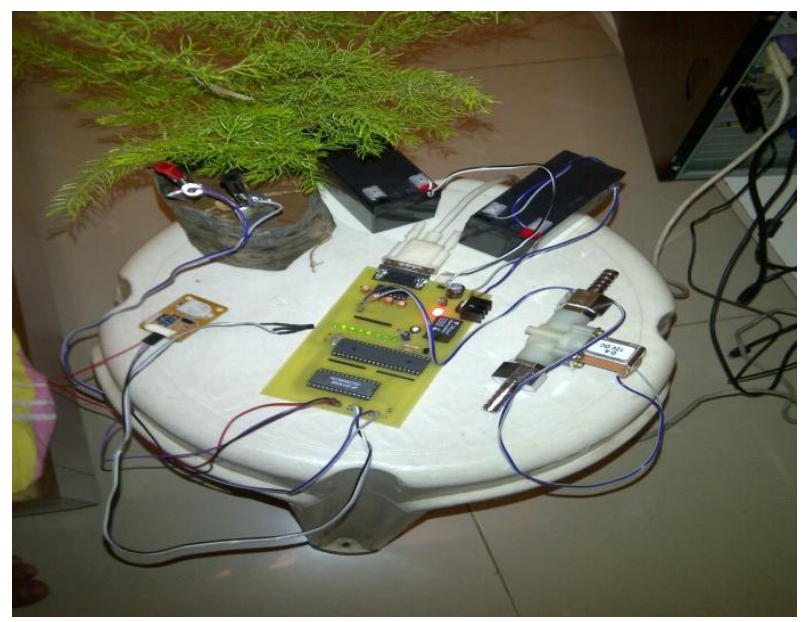

Fig 2. 3 Implementation of the System

\section{CONCLUSION}

The system is relatively simple to design and install and is very useful to all climatic conditions any it is economic friendly. It enhances productivity and reduces water consumption and safe with no manpower is required. Permits other yard and garden work to continue when irrigation is taking place, as only the immediate plant areas are wet. 
Reduces soil erosion and nutrient leaching. Prevents the chance of plant disease by keeping foliage dry.

The key elements that can be considered while designing an advanced mechanical model are:

\subsection{Flow}

You can measure the output of your water supply with a one or five gallon bucket and a stopwatch. Time how long it takes to fill the bucket and use that number to calculate how much water is available per hour. Gallons per minute x $60=$ number of gallons per hour.

\subsection{Pressure (The force pushing the flow)}

Most products operate best between 20 and 40 pounds of pressure. Normal household pressure is $40-50$ pounds.

\subsection{Water Supply \& Quality}

City and well water are easy to filter for drip irrigation systems. Pond, ditch and some well water have special filtering needs. The quality and source of water will dictate the type of filter necessary for your system.

\subsection{Soil Type and Root Structure}

The soil type will dictate how a regular drip of water on one spot will spread. Sandy soil requires closer emitter spacing as water percolates vertically at a fast rate and slower horizontally. With a clay soil water tends to spread horizontally, giving a wide distribution pattern. Emitters can be spaced further apart with clay type soil. A loamy type soil will produce a more even percolation dispersion of water.

Deep-rooted plants can handle a wider spacing of emitters, while shallow rooted plants are most efficiently watered slowly (low gap emitters) with emitters spaced close together. On clay soil or on a hillside, short cycles repeated frequently work best. On sandy soil, applying water with higher gap emitters lets the water spread out horizontally better than a low gap emitter.

\subsection{Timing}

Watering in a regular scheduled cycle is essential. On clay soil or hillsides, short cycles repeated frequently work best to prevent runoff, erosion and wasted water. In sandy soils, slow watering using low output emitters is recommended. Timers help prevent the too-dry/too-wet cycles that stress plants and retard their growth. They also allow for watering at optimum times such as early morning or late evening.

\subsection{Watering Needs}

Plants with different water needs may require their own watering circuits. For example, orchards that get watered weekly need a different circuit than a garden that gets watered daily. Plants that are drought tolerant will need to be watered differently than plants requiring a lot of water.

\section{ACKNOWLEDGMENTS}

I take this opportunity to express gratitude to-wards my guide prof Ms. Neha More of department of computer science (cse) and technician Ms. Kimaya Mayekar of Shri Bhagubhai Mafatlal Polytechnic, Mumbai for her constant encouragement and guidance.

Also, I should like to take the opportunity to thanks $\mathrm{Mr}$. Y.I.SHAH (DEAN) and Mr. Janardan S. Kulkarni (HOD) for permitting me to pursue this project

\section{REFERENCES}

[1] www.engineersgarage.com. Available at: 2 in 1 Doorbell

[2] www.8051 projects.com available at: Free Microcontroller Projects - 8051-AVR-PIC

[3] The 8051 Microcontroller and Embedded Systems Using Assembly - Muhammed Ali Mazidi, Janice Gillespie Mazidi, Rolin d. Mckinlay

[4] Embedded Systems - Raj Kamal

[5] www.dnatechindia.com/phocadownload/Sensors/sy-hs220.pdf - (Humidity Sensor DATA SHEET)

[6] System Analysis And Design - Elias M.Awad

[7] www.ti.com/lit/ds/symlink/lm35.pdf - (temperature sensor DATASHEET

[8] www.national.com/ds/AD/ADC0808.pdf - (ADC DATA SHEET)

[9] http://www.robosapiensindia.com/resources/max232.pdf - (MAX232 DATASHEET) 